\title{
KNOWLEDGE CONVERGENCE IN COLLABORATIVE LEARNING: CONCEPTS AND ASSESSMENT
}

This is a post -print of an article submitted for consideration in the Learning \& Instruction $\mathbb{C}$ 2007 Elsevier.

Personal use of this manuscript is permitted. Permission from Elsevier must be obtained for any other commercial purpose.

This article may not exactly replicate the published version, due to editorial changes and/or formatting and corrections during the final stage of publication. Interested readers are advised to consult the published version which can be found at:

http://www.sciencedirect.com/science/article/pii/S0959475207000539

doi: $\{10.1016 /$ j.learninstruc.2007.03.007 \}

Please refer this manuscript as:

Weinberger, A., Stegmann, K., \& Fischer, F. (2007). Knowledge convergence in collaborative learning: Concepts and assessment. Learning and Instruction, 17(4), 416-426. 
Running head: KNOWLEDGE CONVERGENCE

\author{
Knowledge Convergence in Collaborative Learning: \\ Concepts and Assessment
}

\author{
Armin Weinberger ${ }^{1}$ \\ Karsten Stegmann \\ Frank Fischer \\ Ludwig-Maximilans-Universität München
}

\footnotetext{
${ }^{1}$ Correspondence can be sent to Armin Weinberger, Ludwig-Maximilians-Universität, Chair of Education and Educational Psychology, Department of Psychology, Leopoldstr. 13, 80802 Munich, Germany. Fax: +49+89 2180996889 E-mail: armin.weinberger@psy.lmu.de
} 


\begin{abstract}
In collaborative learning the question has been raised as to how learners in small groups influence one another and converge or diverge with respect to knowledge. Knowledge convergence can be conceptualised as knowledge equivalence and as shared knowledge prior to, during, and subsequent to collaborative learning. Knowledge equivalence refers to learners becoming more similar to their learning partners with regard to the extent of their individual knowledge. Shared knowledge means that learners have knowledge on the very same concepts as their learning partners. In this article, we provide measures for assessing both, knowledge equivalence and shared knowledge.
\end{abstract}

Keywords: Knowledge convergence, shared knowledge, Computer-Supported Collaborative Learning, collaborative learning 


\section{KNOWLEDGE CONVERGENCE IN COLLABORATIVE LEARNING: CONCEPTS AND}

\section{ASSESSMENT}

Various collaborative learning approaches are based on the idea that learners influence one another when learning together (e.g., De Lisi \& Goldbeck, 1999). One important aspect of this mutual influence is that knowledge is exchanged and converges through social interaction (Barron, 2003; Roschelle, 1996; Ickes \& Gonzales, 1996). Knowledge convergence has been conceptualised as a group-level phenomenon describing how two or more individuals, in socially interacting, are or become similar with respect to their knowledge. Learners who converge in knowledge have been found to benefit more from collaborative learning than learners who did not (Fischer \& Mandl, 2005).

In this article, we will introduce varying conceptualisations of knowledge convergence at different phases of collaborative learning and propose corresponding knowledge convergence measures.

\section{Conceptualising Knowledge Convergence}

In collaborative learning, learners are typically supposed to construct knowledge by working on complex problems together, including individually contributing to solving the problem, partaking in discussion of the individual contributions, and arriving at joint solutions (Roschelle \& Teasley, 1995). Within this collaborative process, learners may adopt ideas from their peers and after collaborating share (i.e., have in common) specific ideas. There are also indications, however, that learners may differentially benefit from learning together, depending on their individual prerequisites, and diverge in knowledge, i.e. individuals within a group are or become more dissimilar with respect to their knowledge (Webb, Ender, \& Lewis, 1986). Knowledge convergence / divergence can be conceptualised differently at varying stages of collaborative learning. A main distinction can be made between knowledge equivalence and shared knowledge. Knowledge equivalence refers to learners becoming more 
similar to their learning partners with regard to the extent of their individual knowledge. By shared knowledge, we mean that learners have knowledge on the very same concepts as their learning partners.

Knowledge equivalence and shared knowledge may relate to individual learning outcomes in different ways prior to, during, and subsequent to collaborative learning. First, we will conceptualise knowledge equivalence and shared knowledge and their importance for collaborative learning at these different stages. Second, we will introduce measures for knowledge equivalence and shared knowledge.

\subsection{Prior knowledge and its distribution among group members}

The similarity of knowledge prior to collaborative learning can be conceptualised in at least two differing, yet complementary ways. Prior knowledge equivalence alludes to learners in a group possessing a similar degree of knowledge regarding a specified subject prior to collaborative learning, regardless of the specific concepts constituting knowledge content. A study by Fischer (2001) showed that dyads with low prior knowledge equivalence acquired more knowledge in unstructured discussions than dyads with high prior knowledge equivalence. This study further demonstrated that prior knowledge convergence may interact with specific instructional support methods, in this case computer-supported collaboration scripts. Learners in knowledge convergent dyads were substantially supported in their knowledge acquisition by a collaboration script structuring learner interaction by assigning the roles of explainer and listener. However, the same collaboration script seemed to be a hindrance for knowledge divergent dyads. These may have been able to apply effective interaction patterns for themselves. The script appeared to interfere with the spontaneously emerging interaction patterns in so far as it assigned the roles of explainer and listener without considering the individual learning prerequisites or the distribution of these prerequisites within the group. 
A further way in which the similarity of knowledge prior to collaborative learning can be conceptualised is shared prior knowledge, which refers to the knowledge of specific concepts that learners within a group have in common. Collaborative learning is often based on the idea that learners possess different learning resources and unshared prior knowledge, i.e. knowledge that their learning partner does not have. For instance, jigsaw scenarios of collaborative learning (Aronson, Blaney, Stephan, Silkes, \& Snapp, 1978) require learning partners with complementary knowledge to share their knowledge in order to collaboratively accomplish a learning task. So far, studies on collaborative learning have taken individual prior knowledge into consideration, e.g., when controlling for randomisation of participants. We suggest that the distribution of prior knowledge within small groups of learners also influences collaborative learning and therefore needs to be controlled.

\subsection{Knowledge convergence processes}

Knowledge convergence can also be regarded as processes which take place during collaborative learning and which can be conceptualised in various ways. One approach is based on the idea that, within discourse, learners may contribute ideas to varying or similar extents (knowledge contribution equivalence). To-date, investigations have examined how much and how heterogeneously learners participate in discourse, e.g., by counting the number of turns that the learners took in a discussion, and whether learners' participation was on-task or off-task irrespective of the single ideas contributed to discourse (Cohen, 1994).

Knowledge convergence processes have also centred on the notion that learners may share knowledge through discussion (knowledge sharing), entailing that learners explicate their knowledge in contributing ideas within discourse and that other learners integrate these ideas into their own line of reasoning. Knowledge sharing can be a unidirectional process, whereby learners attain similar knowledge levels with the help of peers, teachers or learning

material, e.g., a learner points out a new idea and a learning partner takes over this idea. There 
are indications, however, that learners particularly benefit from more transactive forms of knowledge sharing in collaborative learning, e.g., when learners construct counterarguments after being confronted with knowledge divergent to their own or when they share a focus in discourse and build on the contributions of their learning partners (see Barron, 2003; De Lisi \& Goldbeck, 1999; Teasley, 1997).

In order to capture these different aspects of knowledge sharing, two complementary measurement approaches have been developed, namely the knowledge level approach and the transactivity approach. The knowledge level approach to analysing knowledge convergence processes proposes that individual contributions in which individual learners externalise knowledge in discourse be identified and compared. The knowledge level approach allows an analysis of the type of knowledge e.g. knowledge of the task and knowledge of the team, which must be shared in order to enhance effective team performance (see Cannon-Bowers \& Salas, 2001). A limitation of the knowledge level approach is, however, that it does not capture the dynamics of how learners construct shared knowledge. It is for example possible that single ideas are co-constructed across the flow of verbal utterances of two or more speakers in face-to-face discourse, whereas asynchronous discussion boards may result in learners contributing ideas in parallel.

The transactivity approach suggests analysing learners' social mode of coconstruction, depicting how strongly and in what ways learners refer to the contributions of their learning partners (Teasley, 1997). Transactivity is the degree to which learners refer and build on others' knowledge contributions, and has been found to be positively related to individual knowledge acquisition in collaborative scenarios (Teasley, 1997). In completing tasks in which they are required to arrive at joint conclusions, learners may build on each others' contributions in different ways and to different degrees. A social mode with a relatively low level of transactivity is the externalisation of new ideas, for instance in starting 
a discussion. Elicitation is a social mode using the learning partner as a resource, typically by asking questions. Furthermore, learners can also build a consensus in various ways, e.g. through quick, integration-oriented or conflict-oriented consensus building (Weinberger \& Fischer, 2006). Whereas quick consensus building signifies the simple acceptance of those ideas which learning partners contributed and primarily serves the continuation of discourse, integration- or conflict-oriented consensus building is seen to mediate learners building on each others' reasoning and sharing knowledge. Conflict-oriented consensus building is regarded as one of the highest transactive social modes, requiring learners to refer to aspects of peers' contributions with which they disagree and provide modified or alternative ideas (Teasley, 1997).

\subsection{Knowledge convergence outcomes}

Knowledge convergence may also be considered an outcome of learning in small groups. Several approaches to collaborative learning highlight the idea that collaborative learners mutually influence the learning outcomes of their partners (e.g., De Lisi \& Goldbeck, 1999; Roschelle, 1996; Teasley, 1997). As a result of this reciprocal influence, groups of learners may have developed shared knowledge that they can apply to jointly solve future problems more efficiently (Cannon-Bowers \& Salas, 2001). Simultaneously, educators might like to ensure that learners benefit equally from learning together. Apart from the collaborative learners' mutual influence, knowledge convergence outcomes can also be a result of being exposed to the same learning material. However, to date, only few studies have systematically considered knowledge convergence outcomes and empirically traced back knowledge convergence outcomes to the social interaction of learners within a group (Fischer \& Mandl, 2005; Jeong \& Chi, 1999). Collaborative learning can facilitate different types of knowledge convergence outcomes. On the one hand, collaborative learning could facilitate the outcome knowledge equivalence of learners, i.e. two or more learners benefit similarly from 
learning together. On the other hand, collaborative learners may acquire shared outcome knowledge, i.e. individual learners of one group possess knowledge on the same specific concepts after collaboration. The few quantitative studies carried out in the field to date show that collaborative learners share surprisingly little knowledge within a specified area compared to that which they could potentially share after learning together, but typically do so, because they have mutually influenced each other in social interaction (Fischer \& Mandl, 2005; Jeong \& Chi, 1999).

$* * * * * * * * * * * * * * * * * * * *$

Insert Table 1 about here

$* * * * * * * * * * * * * * * * * * * *$

\section{Knowledge Convergence Measurement}

In this section we address how the various aspects of knowledge convergence (see table 1) can be measured.

In analysing knowledge convergence some preconditions must be taken into consideration. First, most measures of knowledge convergence depend on what and how individual knowledge is being assessed. This dependency implies, for instance, that the analysis of knowledge convergence regarding single concepts assessed by traditional recall or multiple choice tests captures neither the convergence of understanding of these concepts nor the convergence of knowledge on how they are applied in different contexts. Learners may for example use the same technical terms in such tests, yet have a different understanding of their meaning and how they are applied to problem cases. In contrast, if knowledge is assessed in a meaningful context, whereby learners are asked to apply specific concepts to new and complex problems, knowledge convergence measures can indicate to what extent learners are similarly able to use and apply concepts appropriately in a given context (see Appendix A for an illustration of how we assess knowledge in terms of relations that learners construct 
between concepts and problem case information). A further restriction of this approach is that the knowledge convergence measures are only valid for limited and well-specified areas of knowledge with a limited number of aspects which can be assessed empirically. In learning environments, this typically applies to the knowledge area that is to be learned given that it can be defined a priori and empirically analysed a posteriori. Of course, convergence measures can be applied to any kind of cognitive response (Ickes \& Gonzales, 1996) which can be specified and quantified. Learners may, for instance, acquire knowledge other than that which was initially targeted, i.e. the knowledge they are supposed to learn within a specific learning environment, and converge towards this non-target knowledge, including, for instance, misconceptions. Furthermore, the specified knowledge area needs to be operationalised by different equivalent and independent knowledge items in order to provide a basis of comparison when it comes to learners' knowledge levels, i.e. the items to be learnt should thus be comparably difficult and equally important. Finally, we must exclude alternative explanations to ensure that knowledge convergence outcomes are a consequence of social interaction:

(1) By applying measures that are adjusted for chance concurrence.

(2) By selecting knowledge items of medium difficulty to avoid extremely high or low knowledge scores. The extremes lead to an arithmetic artefact on the convergence scores, namely that learners who knew everything or nothing at all would simultaneously also have perfect knowledge convergence scores.

(3) By comparing real groups of learners who have actually collaborated with each other with nominal groups of learners to control the impact of the same learning resources and the same learning environment. Nominal groups consist of individuals who have learned collaboratively under the same conditions, but with 
different partners than those with whom they are being compared in a (post-hoc) nominal group.

Note that this notion of nominal groups differs from their traditional meaning in social psychology, where such groups consist of individuals working alone on a problem or task and the experimental focus consists of comparisons between group and individual performances. Alternative to the nominal group approach, multilevel modelling or hierarchical level modelling (HLM) can be applied, which is an approach to analyse individual and group level phenomena under the assumption that phenomena on both levels are not independent. Besides enormous requirements for carrying out HLM (see De Wever, Van Keer, Schellens, \& Valcke, this issue; Kreft \& de Leeuw, 1998), this approach does not clarify the type of learners' mutual influence regarding the questions whether learners converge or diverge or whether learners have equivalent knowledge or share knowledge. All of these preconditions of the knowledge measures do not apply when analysing knowledge convergence with the transactivity approach.

In order to facilitate a better understanding of the different concepts which we propose for the various phases of collaborative learning, the following section provides background information on how to assess knowledge convergence.

\subsection{Assessing prior knowledge equivalence}

In general, measures of dispersion can be used to analyse differences in prior knowledge between learners (see Ickes \& Gonzales, 1996). However, most of the measures used, such as for example standard deviation, are dependent on the values they are derived from, so that extremely high or low individual knowledge test scores arithmetically restrict convergence measures (as previously noted). In contrast, the coefficient of variation is defined as the standard deviation of a group divided by the group mean. Thus, the advantage of this measure is that it is normalised and therefore circumvents the production of an arithmetical 
artefact. This measure can be applied in the following procedure for assessment of prior knowledge equivalence. First, individual prior knowledge scores are calculated. Second, standard deviations of the knowledge scores of learners within one group are determined and then aggregated (because this measure of dispersion indicates the extent to which learners deviate and are thus dissimilar from the group mean). Third, the aggregated standard deviations are subsequently divided by the mean to determine the coefficient of variation.

For example in table 2, group A and group B both consist of three members and yield different prior knowledge equivalence values. In group A, each of the learners demonstrates knowledge, e.g., by constructing two different relations between concepts of Weiner's (1985) attribution theory and a specific problem case, in which a student considers himself as "untalented", "lazy", and the task "too difficult" (see Appendix A). In group B, Tina knows how to construct three concept-case relations, whereas Thomas and Tim each know how to construct two concept-case relations prior to their learning together.

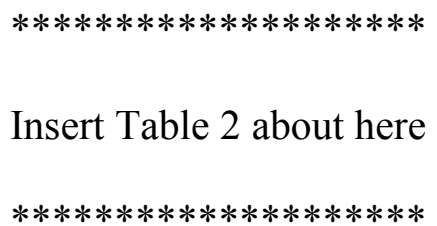

Individual knowledge scores of each learner in group A was 2, thus resulting in a mean of $2(S D=0)$; in group B the scores are 3, 2, and 2 for Tina, Thomas, and Tim respectively. Group B has a mean of $2.33(S D=0.58)$. Prior knowledge in group A is more equivalent than prior knowledge in group $\mathrm{B}$.

The prior knowledge equivalence measure is a relative measure that does not provide information about how much knowledge learners have acquired, since concepts that are not known by any of the group members also contribute to these convergence scores. In this way, high prior knowledge equivalence scores may indicate both knowledge convergence as well 
as the "convergence of ignorance", i.e. that learners equally do not know how to apply specific concepts.

\subsection{Assessing shared prior knowledge}

Assessing shared prior knowledge centres on the idea of comparing learners' individual knowledge prior to collaborative learning. In order to compare the knowledge of one learner with the knowledge of another learner, the specific concepts that learners know must first be assessed. Second, to examine whether learners possess knowledge of the same specific concepts, we suggest pair-wise comparisons of items of a prior knowledge test, which are conducted by comparing all possible pairs of learners within small groups to determine to what degree learners know to apply the same concepts. Third, any pair of learners within a small group that shares the ability to apply a specific concept to a problem case adds to the shared prior knowledge score. Since the measure for shared prior knowledge is based on individual scores and due to the fact that individual learners may have little knowledge on the subject prior to collaborative learning, the measure for shared prior knowledge has to be normalised by dividing it by the mean value of the group.

In groups of more than two members, knowledge may be unshared, partially shared, or completely shared (Klimoski \& Mohammed, 1994). These states can be differentially weighted depending on the theoretical approach and research question. For instance, when all learners of one group of three are able to correctly respond to a knowledge test item, a shared prior knowledge value of 3 is credited to the learning group equalling three "positive" pairwise comparisons. If only two learners are able to respond correctly to this item, a shared prior knowledge value of 1 is credited for one positive pair-wise comparison. In any other case, including a group mean of zero, a shared prior knowledge value of zero is assigned.

\subsection{Assessing knowledge contribution equivalence during collaboration}


In order to measure knowledge contribution equivalence, knowledge externalised in discourse first needs to be identified (see Appendix A). Once the knowledge contributed by individual learners during collaborative learning has been assessed, the procedure for measuring knowledge contribution equivalence remains the same as the procedure for measuring prior knowledge equivalence (see above): First, individual knowledge explicated by learners in discourse is identified. Second, the standard deviations of these knowledge scores within one group are determined and then aggregated. Third, the coefficient of variation is subsequently calculated.

\subsection{Assessing knowledge sharing during collaboration}

Two ways of assessing knowledge sharing during collaboration are to analyse the distribution of the individual knowledge that learners externalise in discourse analogous to assessment of knowledge equivalence and shared knowledge prior and subsequent to collaborative learning (knowledge level approach) on one hand, and to analyse the transactivity of learners' social modes of co-construction (transactivity approach) on the other hand. For an example of discourse analysis applying both approaches, an excerpt of scripted discourse is outlined in Appendix A.

\subsubsection{Knowledge level approach}

First, the individual knowledge contributed by learners in discourse must be identified. Following this, the measure for knowledge sharing is formed analogously to the measure for shared prior knowledge and is based on pair-wise comparisons of learners' contributions during collaborative learning. For each of the small groups of learners, it must be determined whether each possible pair used the same propositional units (concept-case relations). Each of those pairs adds to the knowledge sharing score. Finally, the score is normalised by dividing it by the mean value of the small group.

\subsubsection{Transactivity approach}


To analyse how learners build consensus in discourse, it has been suggested that discourse corpora first be sampled and segmented (see Weinberger \& Fischer, 2006). Knowledge convergence must be assessed on the basis of coherent samples of discourse corpora in order to capture how learners relate to and operate on each others' knowledge contributions. Segmentation of discourse corpora must enable the analysis of learners' mutual references, at the same time as allowing the differentiation of single knowledge contributions upon which learners build consensus. Second, segments are to be coded with respect to different social modes of co-construction. Weinberger and Fischer (2006) distinguish five social modes characterised by different degrees of transactivity, namely externalisation and elicitation as well as quick, integration-oriented, and conflict-oriented modes of consensus building. Externalisation refers to learners contributing new ideas in the group without any reference to prior contributions of their learning partners. This applies for instance, to any initial contribution in a discussion, e.g., "Here is my first analysis of the problem case:". Elicitation denotes learners asking questions of their learning partners in order to induce a reaction and use them as additional learning resources, e.g., "Do you think that this is a stable attribution?". Quick consensus building is a low transactive social mode in which learners accept contributions of their peers without further modifications or comments, e.g. by saying “Ok, I agree". It remains unclear whether learners who quickly build a consensus actually agree with the ideas explicated by their learning partners in discourse, or whether agreement is signalised for momentary purposes only, such as for example in order to move on with the task. The more transactive integration-oriented consensus building indicates the extent to which learners build on the ideas of their peers in discourse. Learners may adopt, integrate or apply knowledge that their learning partners have previously externalised, e.g., A: "Michael attributes to internal, stable causes;" B: “Ok, I have got that now. That means he attributes to talent and that is a detrimental attribution pattern". Conflict-oriented consensus building has 
been argued to constitute an even higher transactive social mode and refers to learners disagreeing, modifying or replacing ideas externalised by their learning partners, e.g., A: "The attribution of the teacher is de-motivating;" B: "Wrong, the attribution of the teacher is beneficial". Conflict-oriented consensus building indicates that learners strongly build on the contributions of their learning partners, at the same time as contributing new and different ideas themselves.

\subsection{Assessing outcome knowledge equivalence}

As a result of learning together, learners may have acquired outcome knowledge equivalence. Assessing outcome knowledge equivalence is analogous to assessing prior knowledge equivalence and knowledge contribution equivalence. First, individual outcome knowledge needs to be measured reliably in individual tests following collaboration. Second, the coefficient of variation can be calculated for each small group of learners and aggregated to form a measure of outcome knowledge equivalence based on specific knowledge items of medium difficulty that learners can or cannot adequately respond to in knowledge post-tests.

\subsection{Assessing shared outcome knowledge}

The measure of shared outcome knowledge is based on pair-wise comparisons of learners of one group with respect to the adequacy of their responses to specific items in an individual knowledge test. Assessing shared outcome knowledge is analogous to assessing shared prior knowledge and knowledge sharing with the knowledge level approach. After pair-wise comparisons of items of a post-test on knowledge, any pair of learners within a small group that shares the ability to apply a specific concept to a problem case adds to the shared outcome knowledge score. As was the case with outcome knowledge equivalence, shared outcome knowledge needs to be controlled for influences other than the influence of social interaction during collaborative learning.

\section{Conclusion}


Investigations involving collaborative learning have often focused on the individual learner and individual activities. However, theoretical approaches to collaborative learning emphasise the role of the learning partner and how the social interactions of learners influence knowledge construction (e.g., Barron, 2003). Measuring knowledge convergence has shown to serve as predictor for later outcomes of groups (e.g., Cannon-Bowers \& Salas, 2001). Randomisation of groups of learners, for instance, should thus not only be checked based on measurements of individual prior knowledge, but also on the distribution of prior knowledge within the learning groups. Investigating knowledge convergence can help to test the theoretical assumptions of learners' mutual influence. Multiple approaches to the analysis of knowledge convergence are needed at this early stage of convergence investigation in collaborative learning. Approaches based on the analysis of learners' social interaction can capture the processes involved in learners' co-construction and exchange of ideas, whereas approaches based on comparisons of learners' knowledge levels at given times can show how members of one and the same group benefit differently (or similarly) from collaborative learning. Applying knowledge convergence measures can help to fine-tune the support of knowledge convergence for collaborative learning. These measures can be used to evaluate theoretical assumptions and to consolidate findings of knowledge convergence in collaborative learning in future studies. Presently, the concept of knowledge convergence constitutes an important approach to understanding the mechanisms of collaborative learning and our measures can be viewed as a starting point in establishing standards for their evaluation. Conversely, investigating knowledge convergence may encourage the development and refinement of theoretical assumptions with respect to collaborative learning. Limitations of quantitatively assessing knowledge convergence. The approaches to the analysis of knowledge convergence presented here, are valid for testing hypotheses based on 
theoretical approaches to collaborative learning that predict learning outcomes based on the mutual influence of learners.

Yet, the presented measures have several limitations, namely (1) the limitation of knowledge as a specifiable quantity, (2) the problem of knowledge that is not externalised, and (3) the ambiguity of individual contributions to discourse.

(1) The knowledge equivalence and the shared knowledge measures are limited to approaches that make assumptions on target knowledge as a specifiable quantity. The suggested knowledge convergence measures are based on content analysis of discourse and written responses to open questions, the results of which are aggregated and quantified to assess individual knowledge. As of yet, there are no simple answers to the questions: "What is knowledge" and "How can it be quantified?". The operationalisation of knowledge into discrete units may resemble an approximation of the construct rather than an unambiguous representation and yet, most of the presented knowledge convergence measures build on a quantification of knowledge. The presented knowledge convergence measures must be carefully interpreted depending on the way in which individual knowledge is being assessed. For instance, given that learners are able to recall the same specific concept in a free recall test, they may still possess divergent understanding of the concept's meaning and the manner in which it is to be applied. At the very least, the approach suggested here is based on propositional units that have proved to carry some psychological reality (e.g., Kintsch, 1998) and measurement further took place in a meaningful context of analysing authentic problems. When applying these convergence measures, future studies should provide detailed information on the conceptualisation and measurement of that which forms the basis of convergence (i.e., their approach to measuring knowledge).

(2) The measures suggested in this article are susceptible to blind spots in analysing individual knowledge when learners choose not to share their thoughts, e.g. when learners 
build consensus quickly without further elaboration of what has been said. Knowledge may to a large extent be constructed on a social plane, but some learners may also choose not to participate in contributing ideas to discourse, instead learning from what they are told by their peers, teachers, or learning material. In assessing this "hidden" knowledge convergence, additional assessment techniques may be necessary, e.g. think-aloud protocols or interviews with individual students in order to investigate what kinds of ideas and thoughts they would not externalise in other tests.

(3) The measures are susceptible to ambiguity of learners' contributions. For instance, learners may repeat contributions of their learning partners as a counter-argument, as a summary, or as something else. These ambiguities may be revealed by studying single cases of collaborative learning. These studies may in turn serve to generate further hypotheses on more complex mechanisms of knowledge convergence, which in turn can be tested quantitatively in later stages of investigating knowledge convergence in collaborative learning, like, for example, collaborative completions (Barron, 2003; Roschelle \& Teasley, 1993).

Studies show how instructional support may (beyond influencing individual learning) also influence the distribution of learners' contributions to discourse in small groups. Thus, in analysing the way in which instructional support influences knowledge convergence in collaborative learning, we may learn how such support can be improved regarding effects on knowledge convergence and its influence on individual outcomes respectively. Furthermore, collaborative learning does not only aim to support individual knowledge construction, but also the co-construction and convergence of knowledge (Roschelle, 1996).

This article focused on the conceptualisation of knowledge convergence phenomena and further suggested some measures applicable to these phenomena. We raised a number of red flags and indicated several limitations of knowledge convergence assessments in order to 
help future studies avoid some of the pitfalls associated with measuring knowledge convergence. We also discussed important limitations in measuring knowledge convergence and clarified at which points other approaches to the assessment of convergence and divergence in cognitive and social processes are more appropriate. Future studies in collaborative learning may apply the knowledge convergence measures along with other methods of assessment (e.g., HLM) and thus accumulate further scientific knowledge on how learners construct knowledge by mutually influencing each other in social interaction. 
References

Aronson, E., Blaney, N., Stephan, G., Silkes, J., \& Snapp, M. (1978). The jigsaw classroom. Beverly Hills, CA: Sage.

Barron, B. (2003). When smart groups fail. The Journal of the Learning Sciences, 12, $307-$ 359.

Cannon-Bowers, J. A., \& Salas, E. (2001). Reflections on shared cognition. Journal of Organizational Behavior, 22, 195-202.

Cohen, E. G. (1994). Restructuring the classroom: Conditions for productive small groups. Review of Educational Research, 64, 1-35.

De Lisi, R., \& Goldbeck, S. L. (1999). Implication of Piagetian theory for peer learning. In A. M. O'Donnell \& A. King (Eds.), Cognitive perspectives on peer learning (pp. 3-37). Mahwah, NJ: Erlbaum.

De Wever, B., Van Keer, H., Schellens, T., \& Valcke, M. (this issue). Applying multilevel modelling to content analysis data: Methodological issues in the study of role assignment in asynchronous discussion groups. Learning \& Instruction.

Fischer, F. (2001). Gemeinsame Wissenskonstruktion. Analyse und Förderung in computerunterstützten Kooperationsszenarien [Collaborative knowledge construction. Analysis and facilitation in computer-supported collaborative scenarios]. Unpublished professorial dissertation, Ludwig Maximilian University of Munich, Germany.

Fischer, F., \& Mandl, H. (2005). Knowledge convergence in computer-supported collaborative learning: The role of external representation tools. The Journal of the Learning Sciences, 14, 405-441.

Ickes, W., \& Gonzalez, R. (1996). "Social" cognition and social cognition. In J. L. Nyle \& A. M. Brower (Eds.), What's social about social cognition? Research on socially shared cognition in small groups (pp. 285-308). Thousand Oaks, CA: Sage. 
Jeong, H., \& Chi, M. T. H. (1999, April). Constructing shared knowledge during collaboration and learning. Paper presented at the AERA Annual Meeting, Montreal, Canada.

Kintsch, W. (1998). Comprehension: A paradigm for cognition. Cambridge, UK: University Press.

Klimoski, R., \& Mohammed, S. (1994). Team mental model: Construct or metaphor. Journal of Management, 20, 403-437.

Kreft, I., \& de Leeuw, J. (1998). Introducing multilevel modelling. London: Sage.

Roschelle, J., \& Teasley, S. D. (1995). The construction of shared knowledge in collaborative problem solving. In C. O`Malley (Ed.), Computer supported collaborative learning, (Vol. 128, pp.69-97). Berlin: Springer.

Roschelle, J. (1996). Learning by collaborating: Convergent conceptual change. In T. Koschmann (Ed.), CSCL: Theory and practice of an emerging paradigm (pp. 209248). Mahwah, NJ: Erlbaum.

Teasley, S. (1997). Talking about reasoning: How important is the peer in peer collaboration? In L. B. Resnick, R. Säljö, C. Pontecorvo \& B. Burge (Eds.), Discourse, tools and reasoning: Essays on situated cognition (pp. 361-384). Berlin: Springer.

Webb, N. M., Ender, P., \& Lewis, S. (1986). Problem-solving strategies and group processes in small groups learning computer programming. American Educational Research Journal, 23, 243-261.

Weinberger, A., \& Fischer, F. (2006). A framework to analyze argumentative knowledge construction in computer-supported collaborative learning. Computers \& Education, 46, 71-95.

Weinberger, A., Ertl, B., Fischer, F., \& Mandl, H. (2005). Epistemic and social scripts in computer-supported collaborative learning. Instructional Science, 33, 1-30. 
Weiner, B. (1985). An attributional theory of achievement motivation and emotion.

Psychological Review, 92, 548-573. 
Table 1

Overview of knowledge convergence concepts prior to, during, and subsequent to collaborative learning

\begin{tabular}{|c|c|c|}
\hline & Knowledge Cor & ergence Concepts \\
\hline Measuring Times & $\begin{array}{c}\text { Knowledge Equivalence and its } \\
\text { Type of Measurement }\end{array}$ & $\begin{array}{c}\text { Shared knowledge and its } \\
\text { Type of Measurement }\end{array}$ \\
\hline $\begin{array}{l}\text { Prior to interaction } \\
\text { (Pre-test) }\end{array}$ & $\begin{array}{l}\text { Prior Knowledge Equivalence: } \\
\text { Coefficient of Variation }\end{array}$ & $\begin{array}{l}\text { Shared Prior Knowledge: } \\
\text { Pair-wise Comparisons }\end{array}$ \\
\hline $\begin{array}{l}\text { During interaction } \\
\text { (Process analysis) }\end{array}$ & $\begin{array}{l}\text { Knowledge Contribution } \\
\text { Equivalence: } \\
\text { Coefficient of Variation }\end{array}$ & $\begin{array}{l}\text { Knowledge Sharing } \\
\text { a) Knowledge Level: } \\
\text { Pair-wise Comparisons } \\
\text { b) Transactivity: } \\
\text { Analysis of Social Modes } \\
\text { of Co-Construction }\end{array}$ \\
\hline $\begin{array}{l}\text { Outcome of } \\
\text { interaction } \\
\text { (Post-test) }\end{array}$ & $\begin{array}{l}\text { Knowledge Outcome } \\
\text { Equivalence: } \\
\text { Coefficient of Variation }\end{array}$ & $\begin{array}{l}\text { Shared Outcome Knowledge: } \\
\text { Pair-wise Comparisons }\end{array}$ \\
\hline
\end{tabular}


Table 2

Two groups of three learners, each of which is able to construct a different set of adequate relations between concepts of a given theory and case information

\begin{tabular}{|l|ccc|ccc|}
\hline \multicolumn{1}{|c|}{ Concept-case relations } & \multicolumn{3}{|c|}{ Group A } & \multicolumn{3}{c|}{ Group B } \\
(1a) Talent $=$ Stable attribution & Leo & Lawrence & Lara & Tina & Thomas & Tim \\
(1b) Talent $=$ Internal attribution & $\mathrm{x}$ & - & - & $\mathrm{x}$ & $\mathrm{x}$ & $\mathrm{x}$ \\
(2a) Effort = Instable attribution & $\mathrm{x}$ & - & - & $\mathrm{x}$ & - & $\mathrm{x}$ \\
(2b) Effort = Internal attribution & - & $\mathrm{x}$ & - & $\mathrm{x}$ & $\mathrm{x}$ & - \\
(3a) Task Difficulty = Instable attribution & - & - & $\mathrm{x}$ & - & - & - \\
(3b) Task Difficulty = External attribution & - & - & $\mathrm{x}$ & - & - & - \\
\hline
\end{tabular}


Table A1

Coding abbreviations for discourse activities and their frequency in the given discourse example

\begin{tabular}{llcc}
\hline Coding Dimensions & Coding Abbreviations & Lena & Anna \\
\hline Concept-Case & $A C C R=$ Adequate Concept-Case Relation & 17 & 3 \\
Relations & $I a C C R=$ Inadequate Concept-Case Relation & - & 2 \\
& $C P S=$ Construction of Problem Space & 1 & - \\
$C C S=$ Construction of Conceptual Space & & -
\end{tabular}

Social Mode of Co- $\quad E x t=$ Externalisation $11-$

Construction

$$
\text { Eli }=\text { Elicitation }
$$

$Q C B=$ Quick Consensus Building

$I o C B=$ Integration-oriented Consensus Building

$C o C B=$ Conflict-oriented Consensus Building

Other

$$
\text { Prompt }=\text { Prompt that was part of the given }
$$




\section{Appendix A: Example of analysis of a scripted discourse excerpt}

The following example of a discussion, which was supported by a specific computersupported cooperation script (see Weinberger, Ertl, Fischer, \& Mandl, 2005) illustrates how knowledge is shared in asynchronous CSCL and coded by us (see Weinberger \& Fischer, 2006 for coding rules; original discussion was in German). The discussion is about a specific problem case about a pupil who suffers from suboptimal attribution patterns of himself and his parents. The learners' task was to build concept-case relations, i.e. apply concepts of attribution theory by Weiner (1985) to information of the problem case. These concept-case relations build the basis for the assessment of knowledge that is being contributed and shared in discourse. Separators $(\mid)$ indicate the segmentation. Whenever learners combined two dimensions of Weiner's attribution theory (1985), e.g. internal stable, two separate segments are counted. Square brackets with three dots $([\ldots])$ indicate an omission of text in this example. Within the curly brackets, the concept-case relation and the social mode of coconstruction is indicated. Table A1 presents a glossary of abbreviations and the overall outcomes of the discourse example in term of the knowledge level approach.

\section{$* * * * * * * * * * * * * * * * * * * * * *$}

Insert Table A1 about here

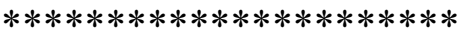

The first message is sent by Lena at 10:12 am, enacting the role of case analyst as suggested by the script (see Weinberger et al., 2005).

| Michael attributes his bad performances to a lack of talent. $\{A C C R / E x t\} \mid$ (internal $\{A C C R /$ $E x t\} \mid$ stable) $\{A C C R / E x t\} \mid$ Mrs. W attributes his bad performances to a lack of effort $\{A C C R$ $/ E x t\} \mid($ internal $\{A C C R / E x t\} \mid$ variable $\{A C C R / E x t\})$ and tries to motivate him anew $\{A C C R / E x t\} \mid$ Michael's parents attribute his bad performances to a lack of talent, as he does. $\{A C C R / E x t\}|[\ldots]|$ The consequences of the attributions of M. himself $\{A C C R / E x t\} \mid$ and 
his parents have insofar rather unfavourable effects on Michael's learning behaviour and his motivation $\{A C C R / E x t\} \mid$ whereas the external attribution of his math teacher has rather positive effects. $\{A C C R / E x t\} \mid$

All propositional units can be regarded as externalisations, as this initial message does not refer to any earlier messages. Lena contributes several adequate concept-case relations (e.g., lack of talent as internal and lack of talent as stable), as well as adequate concept-case relations with respect to the attribution patterns of Michael's teacher and his parents.

Playing the role of a constructive critic and in response to the critic's prompts (capitalised), Anna replies to Lena's first message at 10:29 am.

| THESE ASPECTS OF YOUR ANALYSIS ARE NOT CLEAR TO ME YET: \{prompt | Does not the fact, that M. thinks, he was untalented in math anyway, have negative effects on his effort? $\{A C C R / E l i\}|[\ldots]|$

WE HAVE NOT REACHED CONSENSUS CONCERNING THESE ASPECTS: \{prompt\}| The teacher also does not really have a motivating effect on Michael, because she tells him to work harder $\{I a C C R / C o C B\} \mid$

MY PROPOSAL FOR AN ADJUSTMENT OF THE ANALYSIS IS: \{prompt $\}$ |

She needed to get across to him that he is not completely untalented in math only because it seems to be a family tradition. $\{\operatorname{IaCCR} / \mathrm{CoCB}\} \mid[\ldots]$

Anna plays her role as a constructive critic as intended by the script, by first posing a question and then engaging in conflict-oriented consensus building and offering alternative analyses of the case. Although the reference to motivation "tell Michael to work harder" is not adequate in terms of Weiner's attribution theory (1985), Anna does contribute new ideas by saying that attribution patterns can be modified by training. Anna does not contribute as much target knowledge as Lena (knowledge contribution equivalence) and does not share knowledge in terms of integrating Lena's perspectives into her own, but continues discourse 
in a highly transactive way. Lena replies to Anna's critique at 10:45 am using the prompts that support the role of the case analyst.

| [...] | REGARDING OUR DIFFERENCES OF OPINION: \{prompt $\}$ |

Thinking that he is not talented $\{A C C R / I o C B\} \mid$ has negative effects on his motivation, $\{A C C R / I o C B\} \mid$ because the lack of talent (stable factor) means that all effort is in vain no matter how hard he tries. $\{A C C R / I o C B\}|[\ldots]|$ The teacher attributes his failures to a variable cause, $\{A C C R / C o C B\} \mid$ which means that he is talented in her opinion and could improve by increasing effort. $\{A C C R / C o C B\} \mid$ She does not give up on him but motivates him in my opinion. $\{A C C R / C o C B\} \mid$ She also says that lack of talent within the family is a mere excuse. $\{C P S / C o C B\}|[\ldots]|$

With respect to the social modes of co-construction, Lena's reply partly takes on her critique $(I o C B)$, and partly responds in a conflict-oriented manner $(C o C B)$. She expresses knowledge and gives reasons why Michael's attribution pattern impedes his motivation. At 11:00 am, Anna replies:

| THESE ASPECTS ARE NOT CLEAR TO ME YET: \{prompt $\}$ |

Ok, I understood now about motivation and talent. Thank you :-) $\{A C C R / I o C B\}|[\ldots]|$ WE HAVE NOT REACHED CONSENSUS CONCERNING THESE ASPECTS: \{prompt\}| You are right in saying that his teacher does motivate him by not believing in the mathweakness of his family - otherwise he probably would not have passed math. $\{A C C R / I o C B\} \mid$ $[\ldots] \mid$

In this final message, Anna does not contribute any new knowledge, but accepts Lena's elaborations. Anna engages in integration-oriented consensus building and constructs a relation between "motivation" and "not believing in the math-weakness of his family".

Overall, the Lena-Anna-dyad does not attain a high value in knowledge contribution equivalence, since Lena constructs more adequate concept-case relations in her role as a case 
analyst than Anna in her role as a constructive critic. In the end, Lena and Anna share some knowledge with respect to the relationship between motivation and not attributing to a lack of talent inherited within the family. Anna deviates from her role as a constructive critic in her final message and engages in integration-oriented consensus building; indicating that she has adopted some ideas from Lena. 